\title{
Luís Miguel Figueiredo Rodrigues
}

Catholic University of Portugal, Portugal

\section{Nuevos Movimientos Eclesiales}

\section{New Ecclesial Movements}

\begin{abstract}
The new ecclesial movements have a particular focus in recent times in the Church, and have come to be known as the Spring of the Spirit. This article addresses this reality, their characteristics and their potential. It highlights the pastoral opportunity to live and profess the apostolic faith in an ever more authentic way.
\end{abstract}

\section{Keywords}

Ecclesial movements, communities, evangelization.

Es un hecho evidente, para quien se aproxima a la Teología post conciliar, que la pérdida de unidad de la teología es uno de los mayores desafíos actuales para el pensamiento cristiano. Le Guillou intenta dar respuesta a esta situación, proponiendo una teología del Misterio, capaz de devolver una reflexión crítica sistemática al horizonte donde el cristianismo nació: a acogida de la Verdad revelada en la Historia. A categoría de Misterio permite a reflexión teológica encontrar la unidad y el equilibrio en la confesión del cristocentrismo trinitario, capaz de inspirar una acción verdaderamente misionera y pastoral de la Iglesia. Esta es la auténtica confesión apostólica.

El teólogo citado, escribe en su obra El Misterio del Padre ${ }^{1}$, en 1973, que "lo cierto es que a fidelidad al testimonio trinitario que está presente en el corazón de la Iglesia y la congrega en la unidad, es lo que suscitó a lo largo de los siglos las comunidades de vida monástica y de vida apostólica

1 M-J Le Guillou, El Misterio del Padre. Fe de los Apóstoles. Gnosis actuales, ed Encuentro, Madrid 1998. 
en las cuales germinó, apoyándose una sobre otra, la experiencia pastoral y la profundización teológica. En nuestros días, tal como en el pasado, tiene que en estas comunidades donde la fe y la teología se lleguen a restaurarnos sus verdaderos fundamentos. Pero, en el futuro, será en la comunicación de comunidades espirituales libres - que unen en la vida del Espíritu a hombres y mujeres, sacerdotes, religiosos y seglares - donde se desarrollarán los caminos de una renovación espiritual, teológica y misionera, digna del llamamiento profético del Vaticano II"2.

Yo veo aquí una clara apuesta por los Nuevos Movimientos Eclesiales, y la contribución que están llamados a hacer en la Iglesia, donde todos los aspectos y perspectivas de la misma deben ser vistos desde la prisma del Misterio Trinitario.

Estas nuevas organizaciones de apostolado seglar, excepcionalmente dinámicas, a las cuales se refería el Beato Juan Pablo II, en el año 1979, llegarían a ser denominadas con el término genérico de 'movimientos', expresión que ni el Vaticano II ni el Código de Derecho Canónico emplean al referirse a los cristianos seglares, pues hablan más de asociaciones seglares. Juan Pablo II la utilizó en 1981, para referirse a los nuevos movimientos en la Iglesia la cual es, ella misma, movimiento. En la Redemtoris Missio (73) se señala como una novedad surgida recientemente en no pocas Iglesias el gran desarrollo de los movimientos eclesiales, dotados de un fuerte dinamismo misionero.

En la Iglesia estos movimientos sobresalen y llaman la atención por su novedad y por su dinamismo espiritual, misionero y evangelizador; suponen un fuerte interrogante para otras realidades eclesiales más antiguas $\mathrm{y}$ tradicionales que el tiempo ha ido anquilosando y que la modernidad ha hecho que experimenten una amarga decepción de impotencia, así como la ineficacia de sus métodos, incluso aunque tuvieran deseo de evangelizar y no solo de 'mantener la fe'.

\section{Nuevos movimientos eclesiales}

Se llaman 'nuevos' para diferenciarlos de cualquier otra forma de asociación laical. Y se denominan 'movimientos', porque son una expresión profunda del movimiento eclesial, de la Iglesia movimiento, más allá de una actividad.

\footnotetext{
2 Ibidem, p. 267.
} 
Son 'eclesiales' porque pueden pertenecer a ellos cristianos provenientes de las tres vocaciones: seglares, consagrados y ordenados. Si bien en su gran mayoría están compuestos por cristianos seglares.

\section{Identidad de los nuevos movimientos eclesiales}

Estos movimientos son considerados como verdaderos carismas del Espíritu para el tiempo presente. Tienen la característica de estar dotados de una cierta imprevisibilidad, mutabilidad, asombro, profunda novedad, gratuidad y libertad. No podía ser de otra forma, al ser expresión de la acción del Espíritu Santo en la Iglesia.

Todos los nuevos movimientos eclesiales parecen coincidir en las siguientes características:

- Son realidades eclesiales nuevas, preferentemente laicas, diferentes de las precedentes o contemporáneas asociaciones laicales;

- De origen carismático, pues pertenecen a la vida y dinamismo de la Iglesia, no a su estructura o dimensión institucional. No vienen dadas, surgen inesperadamente conforme a la libertad y la imprevisibilidad del Espíritu Santo;

- Con un fuerte impulso misionero en una sociedad secularizada. Tienen como tarea principal la misión en el mundo, en el cual se sitúan como testimonio de aquellos valores cristianos que el vendaval secularista arrasó;

- Nascidas en torno a un fundador, de fuerte personalidad carismática, que ejerce una fuerte atracción, testigo privilegiado de la fe, con una oferta atrayente y significativa, porque es persona del Espíritu;

- Con una doctrina, espiritualidad y metodologías propias, insertas dentro del gran tesoro que es la Iglesia, pero materializadas con un toque particular, específico;

- Viven el acontecimiento cristiano de modo excepcional. La gran novedad de estos movimientos está en la recuperación de aquellas formas de ser cristiano que fueron olvidadas por la gran masa de cristianos. Tratan de encarnar en la vida a Jesucristo, el Señor, y de testimoniarle desde esa experiencia vital;

- Viven en el aquí y ahora de la Iglesia. El rasgo más característico de estos movimientos es que viven muy encarnados en el tiempo presente, con una fuerte comunión teológica, afectiva y efectiva con la Jerarquía, de modo especial con el Papa; 
$244 \quad \begin{aligned} & \text { The Person and the Challenges } \\ & \text { Volume } 3 \text { (2013) Number } 1\end{aligned}$

- Empeñados en una nueva evangelización. El hecho de estar decididos a desempeñar tareas de nueva evangelización deriva de su encuentro existencial con el acontecimiento Jesucristo, en comunión con la Iglesia.

Como conclusión, podemos decir que los nuevos movimientos eclesiales son nuevas realidades eclesiales, preferentemente laicales, de origen carismático, y con un fuerte impulso misionero, en el seno de una sociedad secularizada. Nacieron de un fundador con gran personalidad carismática y tienen espiritualidad y metodologías específicas. En su actuar, viven de manera excepcional el acontecimiento fundante: Jesucristo, empeñados, en Iglesia, en anunciarle aquí y ahora.

\section{Las nuevas comunidades}

Este fenómeno de renovación de las nuevas comunidades tiene su origen en el Concilio Vaticano II, que ve en la experiencia comunitaria de la Iglesia primitiva el modelo y la clave de la renovación eclesial, ya que las nuevas comunidades son aquellos lugares en los cuales se tiene la satisfacción de encontrarse, saludarse, aceptarse y vivir como hermanos en Cristo. Para que sean realmente comunidades eclesiales, Pablo VI en la Evangelii nuntiandi, afirma que deben vivir alimentadas por la Palabra, unidas a la Iglesia particular y universal, en comunión con sus pastores y comprometidas con su entorno. No deben ser sectarias, deben huir de toda reacción sistemática y de un espíritu híper-crítico.

Esta realidad de las nuevas comunidades no surge por casualidad, se fundamenta en raíces antropológicas, teológicas, eclesiológicas y en la Palabra de Dios.

Así:

- Fundamento antropológico. El hombre, desde sus orígenes, huye de la soledad esencialmente porque tiene necesidad de interacción y de sociabilidad;

- Fundamento teológico. Dios es un ser personal y comunitario, por lo que las nuevas comunidades, encarnadas en las realidades terrenas ofrecen al hombre y a la sociedad el Cristo pascual, y al realizarse en ellas el prodigio permanente de Pentecostés, contagian la unidad y la fraternidad universales;

- Fundamento eclesiológico. La Iglesia es la realización visible y misteriosa en la Tierra de la comunión trinitaria. Es Cristo, señal e instrumento de la unidad de todo el género humano y de la unión de todos los hombres entre sí y con Dios. La Trinidad vive en la Tierra, mediante su señal, su sacramento, que es la Iglesia; 
- Fundamento bíblico. Jesús tuvo claramente la voluntad de hacer comunidad. Su mensaje es claramente comunitario. Vino al mundo para instaurar el Reino en el cual se hicieran reales la paternidad de Dios y la fraternidad universal.

Como conclusión, podemos decir que estas nuevas comunidades cristianas pueden definirse como un grupo de cristianos en comunión eclesial, que comparten lo que son, lo que tienen y lo que hacen. Celebran y crecen en la fe, abiertos a la misión, fundamentados en el amor, vínculo que los une en una organización evangélica.

\section{Multiplicidad en la Unidad}

Frente a este fenómeno de los nuevos movimientos eclesiales y de las nuevas comunidades, y su fecunda proliferación en la Iglesia universal, podemos afirmar, con Juan Pablo II, que sólo es admisible aquella pluralidad que constituye «un himno a la unidad».

Este principio de unidad, se debe siempre salvaguardar, y deriva de la comunión en la misma fe, esperanza y caridad, obedientes a Cristo y a los Pastores de Iglesia; es decir, de la comunión en el ser y en el hacer de la Iglesia. Esta es, indudablemente, a mejor clave de clasificación de los movimientos - según Manuel Gonzáles Muñana ${ }^{3}$ - entre las muchas que se podrían hacer.

\section{Objetivos y metodología}

Podemos en este punto comenzando por decir que todos los movimientos coinciden en los objetivos generales, que son: la vivencia experiencial de la fe, la vivencia en comunidad y el carisma de sus fundadores. Esto tiene como consecuencia que todos se esfuercen por vivir la perfección de la caridad, para construir la Iglesia en el tiempo presente, edificando un mundo nuevo.

Después, cada movimiento, tiene su peculiaridad, su forma específica de realizar estos objetivos. Lo que distingue un movimiento de otro es la forma como cada uno realiza los objetivos generales, como los consigue concretar.

\footnotetext{
3 M. Gonzáles Muñana, Nuevos Movimientos Eclesiales, ed San Pablo, Madrid 2001.
} 
The Person and the Challenges
Volume 3 (2013) Number 1

En lo que respecta al método, tenemos de decir que la esencia del cristianismo es el acontecimiento de Cristo y de Su Iglesia: Cristo es el acontecimiento original y la Iglesia essu continuación en el espacio y en el tiempo. Lo que os nuevos movimientos pretenden con sus métodos es posibilitar el encuentro con ese Acontecimiento.

Se fuese preciso catalogar la metodología, seria catalogada como metodología del encuentro con Cristo, donde todo lo demás carece de importancia y es relativizado, procurando cada uno vivir el cristianismo en su primerísima novedad.

Los principales pasos de esta metodología son:

- encuentro con el Señor;

- dejarse mirar por el Señor, y reconocerlo como Dios y Señor;

- seguir a Cristo en radicalidad;

- en un esfuerzo misionero.

Nos caemos en la cuenta, fue esta la metodología que Cristo utilizó con sus discípulos.

\section{Novedad Carismática}

Los nuevos movimientos pertenecen a la vida y dinamismo de la Iglesia, no a su estructura jerárquica; pertenecen a la dimensión carismática, no a la institucional.

Fue el Vaticano II quien devolvió a la Iglesia occidental el termino 'carisma', dándole una gran actualidad. No obstante Pio XII, en la encíclica Mystici corporis ya había hecho referencia a esta realidad. Siendo así el 'carisma' visto como una gracia que procede de Dios, que se da en la Iglesia y en sus miembros, para el bien de la comunidad.

La reflexión teológica, partiendo de la Revelación, acabará dando una definición más acabada de 'carisma', como una gracia, un don gratuito, concedido por el Espiritu a la Iglesia, y en la Iglesia, y a los cristianos para el bien común. Esta gracia es diferente de la santificante, la cual proviene de los sacramentos, pues viene directamente del Espíritu Santo.

Una de las cosas que se debe evitar es contraponer carisma e institución, pues ambas realidades son esenciales. Juan Pablo II, en el mensaje que envió al Congreso Mundial, promovido por el Pontificio Consejo para los Laicos, enseña que: "En la Iglesia no existe contraste o contraposición entre la dimensión institucional y la dimensión carismática, de la cual los movimientos 
constituyen una experiencia significativa. Ambas son coesenciales a la constitución divina de la Iglesia fundada por Cristo".

\section{En el contexto del Vaticano II}

La Iglesia salida del Concilio Ecuménico Vaticano II estaba necesitando de estos nuevos carismas, realidad a la que el Espíritu dio respuesta. La atrofia eclesial llegó a ser alarmante, unos años después de terminar el Concilio: muchos sectores perdían su identidad, buscando en la sociedad secular su seguridad. Fue una época en que sobraron ideas y faltó una vida autentica de encuentro con el acontecimiento original y originante que es Jesucristo, capaz de desencadenar una conversión que predispone al convertido a vivir según esa conversión. Estaba un poco olvidada la realidad de que es Cristo quien transforma la existencia; que la Iglesia y los cristianos tienen por patria el camino y por tarea la misión.

En un estado de tal postración, y cuando menos se esperaba, el Espíritu Santo irrumpió en la Iglesia, a aquello que era un 'invierno eclesial' se transformó en una primavera de vida. Estos nuevos movimientos ofrecen a la Iglesia actual su vida en comunión, expresada en comunidades, en las cuales comparten el camino que conduce del desierto a la tierra prometida.

\section{En una sociedad secularizada}

No es sólo la Iglesia post Vaticano II, también la sociedad contemporánea de la pos-modernidad está necesitada de la existencia de estas nuevas realidades eclesiales. Esta sociedad de masas, con falta de intimidad, súper organizada y burocrática, sin gratitud y sin poesía, agresiva y tecnificada, hace difícil la existencia de las personas, incapaces de adaptarse a un mundo en desarrollo permanente, bloqueado en su afectividad, en su psiquismo y en su voluntad de convivencia.

Los nuevos movimientos y las comunidades ofrecen alternativas muy significativas a la sociedad pos-moderna, tecnócrata, encerrada en el raciocinio científico, que la reviste de consumismo, pero también a la Iglesia y a las grandes religiones históricas, inmersas en buenaparte, en el racionalismo ético-metafísico.

Estos nuevos movimientos se sitúan en esta sociedad de dos maneras: como fermento en la masa y como mediación. Estos nuevos movimientos, en tanto que laicales y peculiarmente seculares, están llamados a impregnar la sociedad del espíritu cristiano y a ser testigos del Señor, a partir de su inserción en la comunidad humana. 


\section{Características}

Estos nuevos movimientos se revisten de unas características que, no siendo exclusivamente suyas, pero perteneciendo a la riqueza de la Iglesia en general, en ellos se revisten de una peculiaridad especial.

Estos movimientos son:

- Laicales, no sólo por estar integrados en su mayoría por laicos, sino sobre todo por su origen, espiritualidad y misión seculares;

- Comunitarios pues, en el seno de la Iglesia estos movimientos constituyen una fuerte invitación a la experiencia de comunidad. Los nuevos movimientos quieren ofrecer a sus contemporáneos el ambiente tierno de la casa del Padre.

- Primacía de la experiencia una vez que la esencia de la comunión con Dios es la experiencia del encuentro con el Señor, generadora de una gratificante conversión, que lleva a una relación con el Señor y con los hermanos, de la cual nacen corrientes de agua viva que revitalizan existencialmente a quien comparte la misma experiencia, convirtiéndose, a la vez, en un oasis para la sociedad y para la Iglesia. El cristianismo es, para los nuevos movimientos, mucho más que una doctrina o una moral. El actuar cristiano es una consecuencia de la fe, no su esencia.

- Misioneros. Estos movimientos llevan bien insertada en su identidad la misión, pues como carismas son dones para los demás. Como comunidad, manifestada en la comunión de fe y de vida, existen para la misión que Cristo confió a la Iglesia. Todos son responsables de la misión, de acuerdo con su vocación y carisma.

- Universales no sólo por estar en muchos países, tener muchos miembros, sino sobre todo porque participan de la catolicidad de la Iglesia.

- Ecuménicos, procurando a unidad, porque practican un ecumenismo en sentido amplio, en su predisposición de derribar todo lo que sean barreras entre países, razas o culturas. Favorecen la vertiente espiritual del movimiento de la unidad, sobre todo en la oración inter-confesional y en el ecumenismo de vida, conviviendo con todos y trabajando en acciones a favor del hombre y de la sociedad. La oración y la vida, cuando van unidas, generan tal fuerza de comunión y de amor entre los que la comparten que ayudan y posibilitan un cierto deshielo dogmático y doctrinal. 
Además de estas características, podemos todavía subrayar el hecho de que son más carismáticas que organizacionales, primando la gratuidad en detrimento de la eficacia y de mantener una relación filial con el Papa.

\section{Criterios de eclesialidad}

Los nuevos movimientos son dones eclesiales por su origen, vida y misión. Nacen en la Iglesia, viven en ella y existen para la misión que la Iglesia tiene en el mundo. Por eso, estos movimientos se caracterizan por la fidelidad a la Iglesia universal, a través de la fidelidad a la Iglesia particular, y por la fidelidad al carisma. La autosuficiencia de cualquier grupo carismático será un 'suicidio eclesiológico'.

Los criterios de eclesialidad para estos movimientos no son específicos de ellos, antes al contrario, pertenecen a los criterios de eclesialidad de todas las realidades eclesiales.

Recogeremos los criterios que Juan Pablo II apuntaba en la Christifideles Laici:

- primado de la santidad;

- confesión íntegra de la fe apostólica en obediencia al Magisterio;

- comunión firme y convencida con el Papa, centro perpetuo y visible de la unidad universal de la Iglesia, y con el Obispo, principio y fundamento visible de la unidad en la Iglesia particular;

- participación en la evangelización y santificación de la humanidad;

- compromiso social al servicio de la dignidad integral del hombre.

La comunión con la Iglesia es una señal de madurez cristiana, que no se alcanza de una vez para siempre, ni es plenamente satisfactoria desde el principio. Es un proceso que se debe hacer; un camino a recorrer; una meta a alcanzar por etapas.

Los nuevos movimientos eclesiales recorren este camino, haciéndose cada vez más conscientes de la necesaria interrelación en el interior del Pueblo de Dios. No puede ser de otro modo. En tanto que carismas que nacieron en el interior de la Iglesia y que existen para ella, aspiran a la plena comunión eclesial, que llega a su madurez cuando se explicita en la comunión teológica, afectiva y efectiva con el obispo diocesano, lo que les lleva a implicarse activamente en los programas y objetivos de la iglesia local, a ponerse al servicio del bien común y a alejarse de cualquier falso protagonismo. 


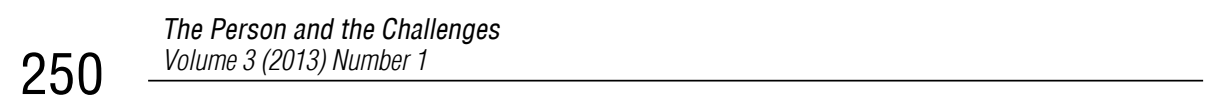

\section{Conclusión}

Para terminar, podemos decir que el mundo es el hogar del hombre, la casa común de la humanidad. Desde la caída del primer hombre, el mundo es una realidad ambigua y ambivalente: lugar donde se realiza la Historia de la Salvación y, al mismo tiempo, espacio herido y castigado por el pecado.

Los nuevos movimientos eclesiales, con su presencia y acción en el mundo, en orden a su renovación y recreación, tratan de conocer a fondo las realidades terrenas y lo que de bello y ordenado hay en cada una, así como su 'maldad'. Valoran rectamente cada situación, comprometiéndose, en el mundo, por la edificación del Reino, siempre en fidelidad a la realidad histórico-salvífica del Misterio trinitario. Los principales campos en los cuales los movimientos realizansu misión son la familia, la cultura, la vida económica y social, la pobreza, el mundo del la clase obrera y los jóvenes.

Esta misión es llevada a cabo por una existencia cristiana marcada por el radicalismo evangélico y un mayor impulso evangélico.

\section{Bibliography}

Bella G., Los nuevos movimientos eclesiales, "Sal Terrae" 100 (2012), p. 933-940.

Canavarro A., Novos movimentos de espiritualidade e interpretação pastoral, "Humanistica e Teologia" 25 (2004), p. 269-289.

Dante F., Los nuevos movimientos eclesiales. Don de Dios y juventud de la Iglesia, "Sal Terrae" 100 (2012), p. 941-954.

Gonzáles Muñana M., Nuevos Movimientos Eclesiales, San Pablo 2001, Madrid.

Guillou Le J-M., El Misterio del Padre. Fe de los Apóstoles. Gnosis actuales, Encuentro 1998, Madrid.

Ioannes Paulus PP. II, Adhortatio Apostolica Post-Synodalis «Christifideles Laici», "Acta Apostolicae Sedis" 81 (1989), p. 393-521.

Leahy B., Ecclesial Movements and Communities. Origins, Significance and issues, New City Press 2011, New York.

Paulus PP. VI, Adhortatio Apostolica «Evangelii Nuntiandi», “Acta Apostolicae Sedis" 63 (1976) p. 5-76.

Terra D., A decisão da fé na cultura das preferências individuais, "Didaskalia” 36 (2006) 1, p. 171-189. 